\title{
Treatment of Landfill Leachate by Using Fenton and Photo-Fenton Processes
}

\author{
Jacek Leszczyński' \\ 1 Bialystok University of Technology, ul. Wiejska 45E., 15-351 Białystok, Poland, e-mail: jleszczynski@pb.edu.pl
}

\begin{abstract}
The paper deals with the study on the use of the Fenton and photo-Fenton process for the treatment of landfill leachates from a stabilized landfill site. The effluents were characterized by $\mathrm{pH}$ of 8.1 , color: $1320 \mathrm{mg} \mathrm{Pt} / \mathrm{L}$, COD of $1670 \mathrm{mg} / \mathrm{L}$, of $\mathrm{BOD}_{5} 155 \mathrm{mg} / \mathrm{L}$, conductivity of $10.3 \mathrm{mS} / \mathrm{cm}$, absorbance of $\mathrm{UV}_{254} 0.332$ and turbidity of 11 NTU. It has been shown that by using Fe(II) and hydrogen peroxide in the Fenton reaction, the organic compounds expressed as COD can be efficiently removed from the effluents. The process was carried out at various doses of $\mathrm{H}_{2} \mathrm{O}_{2}$ and $\mathrm{Fe}(\mathrm{II})$, using different reaction times in the Fenton process and different times of exposure in the photo-Fenton process. The best conditions for the Fenton process were obtained with a Fe/COD ratio of 1.4 and $\mathrm{H}_{2} \mathrm{O}_{2} / \mathrm{Fe}$ molar ratio of 3.2. Under these conditions, the removal efficiency of COD was $85.8 \%$. It was also shown that additional UV irradiation of leachate in the so-called photo-Fenton process and the use of appropriate hydrogen peroxide dosing conditions, can increase the effectiveness of COD removal. The maximum effect of COD removal in the photo-Fenton process was $70.7 \%$ at a dose of $\mathrm{H}_{2} \mathrm{O}_{2} 3.3 \mathrm{~g} / \mathrm{L}$ and a dose of Fe(II) of $0.6 \mathrm{~g} \mathrm{Fe} / \mathrm{L}$. An additional advantage of the photo-Fenton process is the ability to shorten the reaction time and reduce the dose of iron, which can thus reduce the amount of deposits generated.
\end{abstract}

Keywords: landfill leachate, Fenton, photo-Fenton.

\section{INTRODUCTION}

Many technological processes such as coagulation, chemical oxidation, reverse osmosis and ultrafiltration, biological methods as well as deep oxidation methods in which highly reactive free radicals $\mathrm{HO}^{*}$ with high oxidation and reduction potential are generated, are used for the treatment of landfill leachates. These radicals act non-selectively and react quickly with many impurities, including hardly decomposable organic compounds [Wiszniowski et al. 2006, Smol et al. 2014, Talalaj, Biedka 2015]. Deep oxidation methods most often use ozone, $\mathrm{H}_{2} \mathrm{O}_{2}$, UV radiation, catalysts: $\mathrm{Fe}^{2+}, \mathrm{TiO}_{2}$ and combinations: $\mathrm{O}_{3} / \mathrm{UV}, \mathrm{H}_{2} \mathrm{O}_{2} / \mathrm{UV}, \mathrm{O}_{3} / \mathrm{H}_{2} \mathrm{O}_{2} / \mathrm{UV}$. The Fenton process and the modified photo-Fenton process are also used to preliminarily clean up the landfill leachate [Naumczyk et al. 2012, Lopez et al. 2004].
The effectiveness of the Fenton reaction depends, among others, on the $\mathrm{pH}$, dose of reagents and reaction time. The HO' radicals are generated by the Fenton method in accordance with the reaction [Kurniawan at al. 2006]:

$$
\begin{aligned}
& \mathrm{Fe}^{2+}+\mathrm{H}_{2} \mathrm{O}_{2} \rightarrow \mathrm{Fe}^{3+}+\mathrm{HO} \cdot+\mathrm{OH}^{-} \\
& \mathrm{HO} \cdot+\mathrm{H}_{2} \mathrm{O}_{2} \rightarrow \mathrm{HO}_{2}^{\cdot}+\mathrm{H}_{2} \mathrm{O}
\end{aligned}
$$

In the final stage, following reaction takes place:

$$
\mathrm{Fe}^{2+}+\mathrm{HO} \rightarrow \mathrm{Fe}^{3+}+\mathrm{OH}^{-}
$$

The resulting $\mathrm{Fe}^{3+}$ can be re-converted to $\mathrm{Fe}^{2+}$ :

$$
\mathrm{HO}_{2}+\mathrm{Fe}^{3+} \rightarrow \mathrm{Fe}^{2+}+\mathrm{H}^{+}+\mathrm{O}_{2}
$$

The Fenton process can be effectively used to directly remove many impurities. As a result of oxidation, some organic compounds may be converted into more readily biodegradable forms, which enables their further disposal, e.g. by bio- 
logical methods [Peres et al. 2004, Krzemińska et al. 2013]. According to Yoon et al. [1998], coagulation plays a fundamental role in removing the organic impurities from leachates by the Fenton method. Kang et al. [2000] found that the most significant effect on COD removal in the Fenton process is the $\mathrm{Fe}$ (II) dose and the $\mathrm{pH}$, at which the process is carried out.

The Fenton reaction is a recognized method allowing for the removal of color and organic impurities as well as improvement of biodegradation conditions of resistant contaminants present in the leachates from stabilized landfills [Deng et al. 2006, Peres et al. 2004].

Degradation of organic contaminants can be increased in so-called photo-Fenton process, using additional UV irradiation in the reaction of hydrogen peroxide with iron (II). Moreover, the photo-Fenton process leads to the reduction of $\mathrm{Fe}(\mathrm{III})$ to $\mathrm{Fe}(\mathrm{II})$ to form additional hydroxyl radicals by means of photolysis according to the following reaction [Kavitha, Palanivelu 2004, Kim et al. 1997]:

$$
\mathrm{Fe}(\mathrm{III})+\mathrm{h} v \rightarrow \mathrm{Fe}(\mathrm{II})+\mathrm{HO}^{\circ}
$$

The resulting $\mathrm{Fe}(\mathrm{II})$ reacts quickly with $\mathrm{H}_{2} \mathrm{O}_{2}$, which leads to the formation of $\mathrm{HO}^{*}$ radicals.

In the photo-Fenton process, radicals are also formed by reaction [Kurniawan et al. 2006]:

$$
\mathrm{H}_{2} \mathrm{O}_{2}+\mathrm{h} v \rightarrow 2 \mathrm{HO}^{*}
$$

The results of the research, in particular by Kim et al. [1997], indicate better efficiency of purification of leachates treated additionally with UV radiation. At a specific energy input, the oxidation rate was increased to six times the rate without radiation. Furthermore, due to the regeneration of the consumed $\mathrm{Fe}^{2+}$ ions through the irradiation, the amount of ferrous salt to be added can be remarkably reduced.

The purpose of this study was to determine the effectiveness of removing the organic contamination, expressed as the COD indicator, in the stabilized landfill leachate using the classic Fenton reaction and photo-Fenton process.

\section{MATERIAL AND ANALYTICAL METHODS}

The leachate samples for the analyses originated from a solid waste landfill located in the north-eastern part of Poland. The leachate for testing was characterized by an average color of $1320 \mathrm{mg} / \mathrm{L}, \mathrm{COD}$ value of $1670 \mathrm{mg} / \mathrm{L}$, absorbance of $\mathrm{UV}_{254} 0.332$, low turbidity of 11 NTU and $\mathrm{BOD}_{5}$ value of $155 \mathrm{mg} / \mathrm{L}$, while it exhibited a high content of dissolved substances (conductivity $10.3 \mathrm{mS} / \mathrm{cm}$ ). The characteristics of basic indicators of the leachate tested are summarized in Table 1. According to the adopted indicators developed by Kang et al. [2002], the determined $\mathrm{BOD}_{5} / \mathrm{COD}$ ratio of 0.09 in raw leachates indicates a stabilized landfill.

In the technological studies, a $20 \%$ solution of $\mathrm{FeSO}_{4} \times 7 \mathrm{H}_{2} \mathrm{O}$ and a $30 \%$ hydrogen peroxide were used, whereas $\mathrm{H}_{2} \mathrm{SO}_{4} 95-97 \%(w / w)$ and $\mathrm{NaOH}$ were used for neutralization.

The true color was measured with PlatinumCobalt (PtCo color unit) standard method using Hach DR/4000 Spectrophotometer. The biological oxygen demand was measured applying the respirometric method by measuring oxygen pressure decrease using Oxitop bottles. A multifunction WTW inoLab Multi 9310 IDS instrument was used to analyze the $\mathrm{pH}$, conductivity and temperature. The optical absorption spectra (200-800 nm) and ultraviolet absorbance at $254 \mathrm{~nm}\left(\mathrm{UV}_{254}\right.$ absorbance) was measured with a spectrophotometer Merck Pharo 300. The TOC measurements were performed using Analytik Jena TOC multi NC3100 instrument. Other analyses were performed according to Standard Methods [APHA 1998]. In order to report the COD concentration of the treated samples, the interferences caused by residual $\mathrm{H}_{2} \mathrm{O}_{2}$ were avoided, in line with Kang et al. [1998]. The $\mathrm{H}_{2} \mathrm{O}_{2}$ concentration was determined with iodometric method [Klassen et al. 1994].

\begin{tabular}{|c|c|c|}
\hline Parameter & Value & $\begin{array}{l}\text { Standard } \\
\text { deviation }\end{array}$ \\
\hline $\mathrm{pH}$ & 8.1 & 0.12 \\
\hline $\begin{array}{l}\text { Conductivity } \\
(\mathrm{mS} / \mathrm{cm})\end{array}$ & 10.3 & 0.4 \\
\hline $\mathrm{COD}(\mathrm{mg} / \mathrm{L})$ & 1670 & 51.8 \\
\hline $\mathrm{BOD}(\mathrm{mg} / \mathrm{L})$ & 155 & 7 \\
\hline TOC (mg/L) & 440 & 16 \\
\hline Color (Pt-Co units) & 1320 & 53 \\
\hline $\mathrm{UV}_{254} \underset{\left(\mathrm{cm}^{-1}\right)}{\text { absorbance }}$ & 0.332 & 0.013 \\
\hline Turbidity (NTU) & 11 & 0.5 \\
\hline $\mathrm{NH}_{4}{ }^{+}-\mathrm{N}(\mathrm{mgN} / \mathrm{L})$ & 631 & 21 \\
\hline
\end{tabular}

Table 1. Characteristic of landfill leachate 
The removal efficiency of COD was calculated using the following equation:

$$
R=\frac{\left(C_{i}-C_{f}\right) \cdot 100}{C_{i}} \%
$$

where: $C_{i}$ and $C_{f}$ refer to the COD in the landfill leachate before and after the reaction, respectively.

The basic statistic analysis included the calculation of the mean value and standard deviation. The test values are presented as the average of the three measurements, and the standard deviations of measured data were below $5 \%$.

\section{EXPERIMENTAL PROCEDURES}

In the Fenton process, the total sample volume in the reactor was $0.5 \mathrm{~L}$. In the first phase of experiment, the effluents were adjusted to the appropriate $\mathrm{pH}$ using $\mathrm{H}_{2} \mathrm{SO}_{4}$, followed by iron (II) sulfate and hydrogen peroxide dosing. A sample of effluents and reactants was mixed intensively in the reactor with a magnetic stirrer for $20 \mathrm{sec}$ onds at a speed of $110 \mathrm{rpm}$, then slowly for 90 minutes with an the speed of approximately 30 rpm. After slow stirring, the samples were neutralized to $\mathrm{pH} 8$ using a $\mathrm{NaOH}$ solution, again stirred and allowed to sediment for $90 \mathrm{~min}$.

The effect of iron (II) and hydrogen peroxide, reaction time and the method of hydrogen peroxide dosing were studied in the Fenton reaction. The quantities of $\mathrm{Fe}^{2+}$ ions, $\mathrm{H}_{2} \mathrm{O}_{2}$ and $\mathrm{pH} 3$ taken during the experiment were determined based on the literature data and previously conducted author's own research. In each research series, iron (II) was used in the doses of: 0.3, 0.6, 0.9, 1.4 and $2.3 \mathrm{~g} \mathrm{Fe} / \mathrm{L}$, and doses of hydrogen peroxide, in each series respectively: $0.3,0.6,0.9,1.5,2.1$, 2.7, 3.3, 3.9 and $4.5 \mathrm{~g} \mathrm{H}_{2} \mathrm{O}_{2} / \mathrm{L}$.

In the photo-Fenton process, the experiment was carried out using the same process conditions and $\mathrm{pH}$ as in the Fenton process. The tests were carried out at a constant dose of $\mathrm{H}_{2} \mathrm{O}_{2} 3.3 \mathrm{~g} / \mathrm{L}$ and two selected doses of iron (II), i.e. 0.3 and 0.6 $\mathrm{g} / \mathrm{L}$. The samples were tested at specific intervals, namely 15, 30, 60, 90 and 120 minutes. Additionally, in the photo-Fenton process, the samples of effluents were irradiated in a UV reactor. The reactor system consisted of a low-pressure $11 \mathrm{~W} \mathrm{UV}$ lamp placed in a protective tube made of quartz glass, a magnetic stirrer and a cooling system.
The dimensions of the reactor were $7.5 \mathrm{~cm}$ in diameter and $30 \mathrm{~cm}$ in length, respectively. The experiment was carried out at room temperature of $25^{\circ} \mathrm{C}$. Before determination of COD, the samples were filtered through $0.45 \mu \mathrm{m}$ pore size filters.

\section{RESULTS AND DISCUSSION}

\section{Conventional Fenton Treatment}

Due to the adopted doses of $\mathrm{Fe}(\mathrm{II})$ and the $\mathrm{COD}$ value in raw effluents, the $\mathrm{Fe} / \mathrm{COD}$ ratio was in the range of $0.18-1.38$. In their research, Primo et al. [2008] showed that the value of this coefficient over 0.33 does not bring such a significant increase in the effect of COD removal. According to Koc-Jurczyk, Jurczyk [2015], the most effective was the dose of $\mathrm{Fe}^{2+}$ equal $0.5 \mathrm{~g} / \mathrm{L}$ in ratio 1:5. Barbusiński and Pieczykolan [2010] report that the most advantageous dose of $\mathrm{H}_{2} \mathrm{O}_{2}$ and $\mathrm{Fe}^{2+} \mathrm{H}_{2} \mathrm{O}_{2}$ ratio were $1350 \mathrm{mg} / \mathrm{L}$ and 0.2 , respectively at $\mathrm{pH} 3$ and the reaction time of 45 minutes. The $\mathrm{H}_{2} \mathrm{O}_{2} / \mathrm{COD}$ ratio in the Fenton process is based on commonly used values. For example, Deng et al. [2006] state that in the Fenton process, the dose of hydrogen peroxide turns out to be decisive, and the theoretical COD to $\mathrm{H}_{2} \mathrm{O}_{2}$ ratio is $470.6 / 1000$. Due to the COD value in the effluents prior to the process $1670 \mathrm{mg} / \mathrm{L}$ and the $\mathrm{H}_{2} \mathrm{O}_{2}$ dose accepted for the study, the $\mathrm{H}_{2} \mathrm{O}_{2} / C O D$ ratio was in the range from 0.2 to 2.7 . The effect of COD removal after the process, depending on the iron (II) and hydrogen peroxide dose, is shown in Figure 1.

After the Fenton process, the value of impurities expressed as COD varied depending on the dose of hydrogen peroxide and iron (II) from 1069 to $772 \mathrm{mg} / \mathrm{L}$ at a dose of 0.3 to $3.9 \mathrm{~g} \mathrm{H}_{2} \mathrm{O}_{2} / \mathrm{L}$, with the lowest iron (II) dose, i.e. $0.3 \mathrm{~g} \mathrm{Fe} / \mathrm{L}$ and from 735 to $227 \mathrm{mg} / \mathrm{L}$ at the highest iron (II) dose of 2.3 $\mathrm{g} \mathrm{Fe} / \mathrm{L}$. Regarding the values obtained, the effect of COD removal was $36-53.8 \%$ and $56-86.4 \%$, respectively. The studies showed that the greatest influence of reagents on the increase in COD removal efficiency was recorded at a $\mathrm{H}_{2} \mathrm{O}_{2} / \mathrm{Fe}$ molar ratio of 1.5. Above this value, research series, i.e. in the range of $\mathrm{Fe}(\mathrm{II})$ doses applied, from 0.6 to $2.3 \mathrm{~g} \mathrm{Fe} / \mathrm{L}$, no further significant increase in COD removal efficiency was noted in the individual. On the other hand, with the lowest iron (II) dose of $0.3 \mathrm{~g} \mathrm{Fe} / \mathrm{L}$, the intensity of COD removal decreased above the molar ratio $\mathrm{H}_{2} \mathrm{O}_{2} / \mathrm{Fe}=8.2$. 


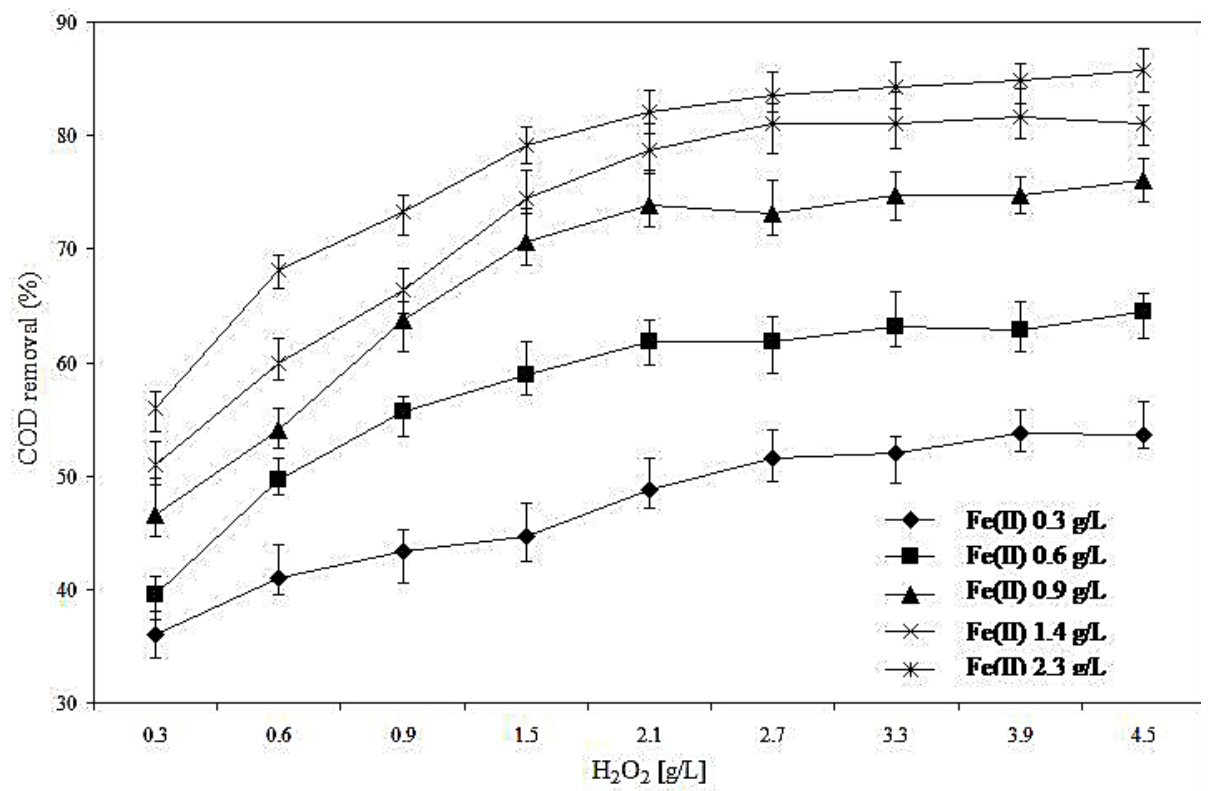

Figure 1. Effectiveness of COD removal in the Fenton process depending on the dose of iron (II) and $\mathrm{H}_{2} \mathrm{O}_{2}$

\section{Effect of Photo-Fenton}

The effectiveness of COD removal in the photo-Fenton process was tested, depending on the iron dose with a constant content of hydrogen peroxide. In addition, an experiment was performed in which the dose of $\mathrm{H}_{2} \mathrm{O}_{2}$ was divided and introduced in three equal time intervals, i.e. at the maximum reaction time every 30 minutes, while at the reaction time of 90 minutes in two doses, also every 30 minutes. The COD changes obtained during the classic Fenton reaction and in the photo-Fenton process are shown in Fig- ure 2. Like in the Fenton process, a rapid drop in COD was observed at a reaction time of 90 minutes; then a slight slowdown of the process was observed. At particular reaction times of 15, 30, 60,90 and 120 minutes and at a molar ratio of $\mathrm{H}_{2} \mathrm{O}_{2} / \mathrm{Fe}=18$, the reduction of COD in the Fenton process without irradiation with a UV lamp was $21.1,35.7,44.8,53$, and $57 \%$. A slightly better effect was obtained with $\mathrm{H}_{2} \mathrm{O}_{2} / \mathrm{Fe}=9$; in this case the COD removal effect was $33.4,45,56.1,63.9$ and $67 \%$. In the photo-Fenton process, the additional irradiation of the sample during the process did not significantly increase the efficiency

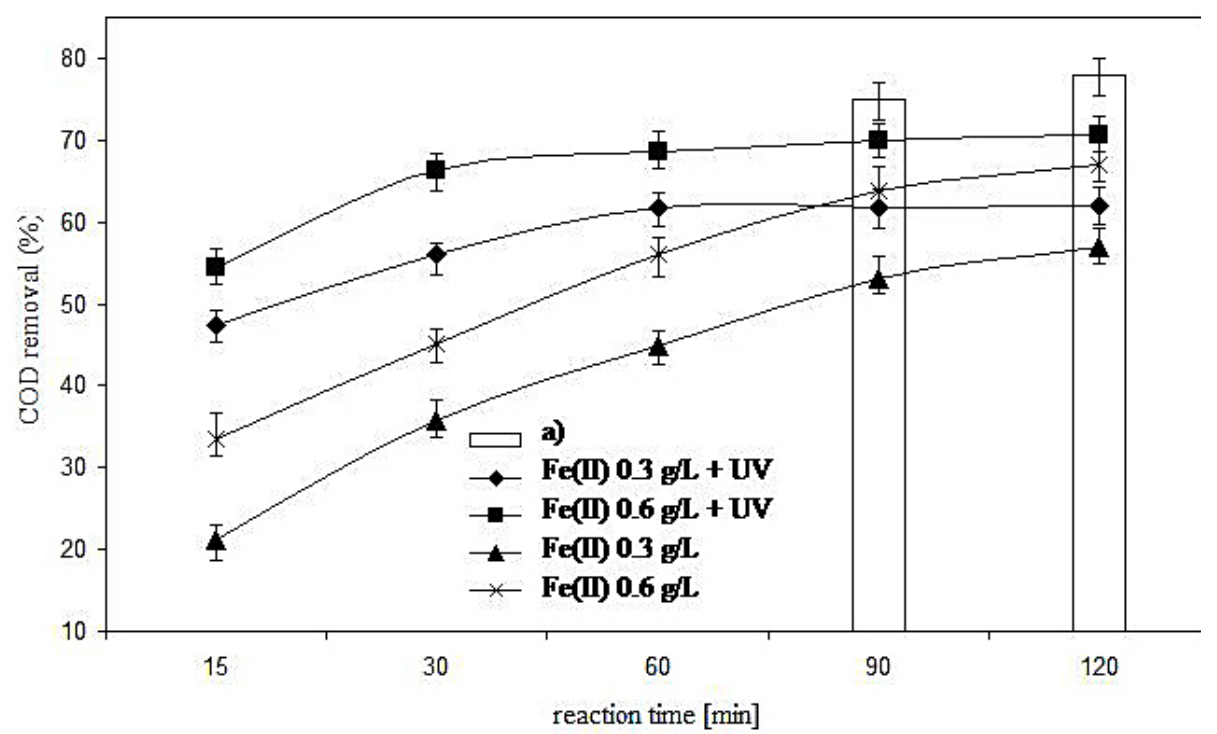

Figure 2. Removal of COD in the Fenton and photo-Fenton processes, depending on the reaction time and iron (II) dose. Dose of $\mathrm{H}_{2} \mathrm{O}_{2} 3.3 \mathrm{~g} / \mathrm{L}$, a) stepwise dosing of $\mathrm{H}_{2} \mathrm{O}_{2}$ in the photo-Fenton process 
of COD removal in the assumed reaction time of 90 and 120 minutes. A similar efficiency of COD removal is shown by the studies carried out by Hermosill et al. [2009].

The maximum COD removal effect of $62 \%$ occurred at a molar ratio of $\mathrm{H}_{2} \mathrm{O}_{2} / \mathrm{Fe}=18$ and reaction time of 90 min., while at $\mathrm{H}_{2} \mathrm{O}_{2} / \mathrm{Fe}=9$ molar ratio, the largest reduction in COD of $70.7 \%$ was recorded with a reaction time of $120 \mathrm{~min}$. Nevertheless, compared to the classic Fenton reaction, a higher intensity of COD removal was observed with a much shorter reaction time in the photoFenton process. Therefore, with a dose of $\mathrm{H}_{2} \mathrm{O}_{2}$ $3.3 \mathrm{~g} / \mathrm{L}$ and $\mathrm{Fe}$ (II) $0.3 \mathrm{~g} \mathrm{Fe} / \mathrm{L}$, the maximum effect of COD removal was recorded already at the reaction time of 60 minutes, while at the iron (II) dose $0.6 \mathrm{~g} \mathrm{Fe} / \mathrm{L}, 66.4 \%$ COD was removed after 30 minutes of reaction. In the case of the photoFenton method, the $\mathrm{H}_{2} \mathrm{O}_{2}$ dosing method was also significant, i.e. with a $\mathrm{H}_{2} \mathrm{O}_{2} / \mathrm{Fe}$ molar ratio of 9 and a reaction time of $90 \%$ and 120 minutes $5 \%$ and $7.3 \%$ higher COD reduction was obtained, respectively, as in the case of a single dose of hydrogen peroxide.

\section{CONCLUSIONS}

1. The obtained research results indicate the possibility of treating the leachate from a stabilized solid waste landfill using both the classic Fenton reaction and the UV-assisted process. In addition, the pre-treatment of leachate using the Fenton reaction is a relatively simple process, which does not require the use of advanced equipment.

2. In the studies using the Fenton reaction, the effectiveness of COD removal was found depending on the dose of hydrogen peroxide and the amount of iron (II), with the highest efficiency of COD removal $85.8 \%$ obtained at a dose of $\mathrm{H}_{2} \mathrm{O}_{2} 4.5 \mathrm{~g} / \mathrm{L}$ and $\mathrm{Fe}(\mathrm{II}) 2.3 \mathrm{~g} / \mathrm{L}$.

3. The photo-Fenton process is an effective method for the degradation of organic pollutants, expressed by the COD indicator, present in the effluents from a stabilized landfill site. The use of the additional irradiation during the Fenton reaction influenced not only the increase in the COD removal efficiency, but also the intensity of the process. In this case, the maximum effect was recorded at a much shorter reaction time, i.e. after just 30 and 60 minutes of irradiation. The studies also showed that the method of dosing the hydrogen peroxide also influences the effectiveness of the process. The maximum effect of COD removal $(70.7 \%)$ in the photo-Fenton process was observed at a molar ratio $\mathrm{H}_{2} \mathrm{O}_{2} / \mathrm{Fe}=9$ and a reaction time of $120 \mathrm{~min}$. At the same time, by changing the $\mathrm{H}_{2} \mathrm{O}_{2}$ dosing method, the COD removal effect increased to $78 \%$.

\section{REFERENCES}

1. APHA (American Public Health Association) 1998. Standard Methods for the Examination of Water and Wastewater. American Public Health Association, Washington, DC.

2. Barbusinski K, Pieczykolan B. 2010. COD removal from landfill leachate using fenton oxidation and coagulation. Architecture, Civil Engineering, Environment, 3(4), 93-100.

3. Deng Y., Englehardt J.D. 2006. Treatment of landfill leachate by Fenton process. Water Research, 40, 3683-3694.

4. Hermosilla, D., Cortijo, M., and Huang, C.P. 2009. Optimizing the treatment of landfill leachate by conventional Fenton and photo-Fenton processes. Science of the Total Environment, 407(11), 3473-3481.

5. Kang K., Shin K., Park H. 2002. Characterization of humic substances present in landfill leachates witch landfill ages and its implications. Water Research, 36, 4023-4032.

6. Kang Y.W., Cho M.J., Hwang K.Y. 1998. Correction of hydrogen peroxide interference on standard chemical oxygen demand test. Water Research, 5, 1247-1251.

7. Kang Y.W., Hwang K.Y. 2000. Effects of reaction conditions on the oxidation efficiency in the Fenton process. Water Research, 34, 2786-2790.

8. Kavitha V, Palanivelu K. 2004. The role of ferrous ion in Fenton and photo-Fenton processes for the degradation of phenol. Chemosphere, 55, 1235-1243.

9. Kim S., Geissen S., Volgepohl A. 1997. Landfill leachate treatment of by a photoassisted Fenton reaction. Water Science \& Technology, 35, 239-248.

10. Klassen N.V., Marchington D., McGowan H.C.H. 1994. H2O2 determination by the I3- method and by $\mathrm{KMnO} 4$ titration. Analytical Chemistry, 66(18), 2921-2925.

11. Koc-Jurczyk J., Jurczyk L. 2015. The efficiency of landfill leachate treatment using the Fenton's reagent. Journal of Ecological Engineering, 16(3), 70-76.

12. Krzemińska D., Neczaj E., Borowski G. 2015. Advanced oxidation processes for food industrial 
wastewater decontamination. Journal of Ecological Engineering, 16(2), 61-71.

13. Kurniawan T.A., Lo W.H., Chan G.Y.S. 2006. Radicals catalyzed oxidation reactions for degradation of recalcitrant compounds from landfill leachate. Chemical Engineering Journal, 125, (1), 35-57.

14. Lopez A., Pagano M., Volpe A., Di Pinto A. 2004. Fenton's pretreatment of mature landfill leachate. Chemosphere, 54, 1000-1005.

15. Naumczyk J., Prokurat I., Marcinowski P. 2012. Landfill leachates treatment by/UV, O3/H2O2, modified Fenton, and modified photo-Fenton methods. International Journal of Photoenergy, Article ID 909157, 1-9.

16. Peres J.A., Beltran de Heredia J., Dominguez J.R. 2004. Integrated Fenton's reagent - coagulation flocculation process for the treatment of cork processing Wastewater. Journal of Hazardous Materials, 107(3), 115-121.

17. Primo O., Rivero M.J., Ortiz I. 2008. Photo-Fenton process as an efficient alternative to the treatment of landfill leachates. Journal of Hazardous Materials, 153, 834-842.

18. Smol M., Włodarczyk-Makuła M., Mielczarek K., Bohdziewicz J. 2014. Comparison of the retention of selected PAHs from municipal landfill leachate by RO and UF processes. Desalination and Water Treatment, 52(19-21), 3889-3897.

19. Talalaj I.A., Biedka P. 2015. Impact of concentrated leachate recirculation on effectiveness of leachate treatment by reverse osmosis. Ecological Engineering, 85, 185-192.

20. Wiszniowski J., Robert D., Surmacz-Górska J., Miksch K., Weber J.V. 2006. Landfill leachate treatment methods: a review. Environmental Chemistry Letters, 4, 51-61.

21. Yoon J., Cho S., Cho Y., Kim S. 1998. The characteristics of coagulation of Fenton reaction in the removal of landfill leachate organics. Water Science \& Technology, 38, 209-214. 